\title{
Program Sehat Tanpa Napza untuk Meningkatkan Drug Use Resistance Self-Efficacy: Prevensi Primer Penyalahgunaan Napza pada Remaja
}

\author{
Hasan Fahrur Rozi' E Maria Goretti Adiyanti $^{2}$ \\ ${ }^{1}$ Pusat Kesehatan Masyarakat Bantul; 1,2Fakultas Psikologi Universitas Gadjah Mada
}

\begin{abstract}
This research aimed to assess the influence of program sehat tanpa napza on drug use resistance self-efficacy. Quasi experiment (untreated control group design with dependent pretest and posttest) was used as the design of the study. The participants of this study were eight grader students from two junior high schools in Yogyakarta, which $X$ junior high school was the experimental group and $\mathrm{Y}$ junior high school was the control group. Drug use resistance self-efficacy was measured with drug use resistance self-efficacy scale modified from Carpenter (2006). The data was analyzed with anova mixed design using SPSS. The result show that Program Sehat Tanpa Napza did not significantly increase drug use resistance self-efficacy in experimental group of adolescent compared with control group ( $F$ $=1.056 ; p>0.05)$. However, adolescent's drug use resistance self-efficacy in experimental group were increased significantly.
\end{abstract}

Keywords : drug use resistance self-efficacy; primary prevention; program sehat tanpa napza

Abstrak. Penelitian ini bertujuan untuk mengetahui pengaruh Program Sehat Tanpa Napza yang merupakan program prevensi primer dengan pendekatan social influence untuk meningkatkan drug use resistance self-efficacy. Penelitian ini merupakan eksperimen kuasi dengan desain untreated control group design with dependent pretest and posttest. Partisipan pada penelitian ini adalah siswa kelas VIII dari dua SMP di kota Yogyakarta, dimana SMP X sebagai kelom pok eksperimen dan SMP Y sebagai kelompok kontrol. Drug use resistance self-efficacy akan diukur dengan skala drug use resistance self-efficacy yang dimodifikasi dari Carpenter (2006). Hasil analisis data menggunakan uji anava campuran menunjukkan bahwa Program Sehat Tanpa Napza tidak dapat meningkatkan drug use resistance self-efficacy pada remaja di kelompok eksperimen dibandingkan dengan kelom pok kontrol secara signifikan $(F=1,056 ; p$ $>0,05)$. Namun demikian, Program Sehat Tanpa Napza dapat meningkatkan meningkatkan drug use resistance self-efficacy kelom pok eksperimen secara signifikan dalam pengukuran dua pekan setelah intervensi.

Kata kunci : drug use resistance self-efficacy; prevensi primer; program sehat tanpa napza

Kesehatan mental remaja menjadi salah satu fokus utama masalah kesehatan mental ataupun kesehatan secara umum (Kieling, Graeff-Martins, Hamoda, \& Roh- de, 2014). Hal ini tidak terlepas dari adanya bukti penelitian yang menunjukkan bahwa berbagai gangguan yang terdiagnosa pada masa dewasa

\footnotetext{
1 Korespondensi mengenai isi artikel ini dapat dilakukan melalui hasan.fahrur.rozi@mail.ugm.ac.id

2 atau melalui adiyanti_psy@ugm.ac.id 
memiliki akar masalah pada masa remaja (Knopf, Park, \& Mulye, 2008). Beberapa faktor psikologis seperti harga diri, optimisme (Ames, Rawana, Gentile, \& Morgan, 2015), resiliensi (Mulyati, 2009), efikasi diri (Sobti, 2010) diketahui dapat melindungi remaja dari beberapa macam gangguan psikologis. Memiliki faktor protektif perlu diimbangi dengan meminimalkan berbagai faktor risiko seperti paparan terhadap kekerasan, paparan terhadap Narkotika, Psikotropika, dan Zat Adiktif (Napza), dan kurangnya lingkungan yang mendidik ataupun lingkungan yang mendukung perkembangan psikososial remaja (Kieling et al., 2014).

Salah satu masalah kesehatan mental yang perlu ditangani secara serius pada remaja adalah masalah penyalahgunaan Napza. Hal ini dikarenakan banyaknya dampak negatif yang ditimbulkan baik untuk diri sendiri ataupun orang lain (Hidayat, 2016). Dampak negatif bagi diri penyalahguna Napza yang mengalami kecanduan adalah adanya kondisi substance intoxification, yaitu perilaku maladaptif yang terjadi sementara dan efek tambahan berupa substance withdrawal yang dapat menimbulkan distress serta kecemasan (Halgin \& Whitbourne, 2010). Berbagai macam gangguan fisik seperti kerusakan otak (Possi, 1996), TBC, AIDS, dan Hepatitis C (Badan Narkotika Nasional [BNN], 2015) juga merupakan dampak penyalahgunaan Napza.

Pecandu Napza berisiko mengalami permasalahan dalam hal perilaku (Possi, 1996), seperti perilaku agresif (Barthelemy, Richardson, Cabral, \& Frank, 2016), perilaku seksual berisiko (Pillon, O'brien, \& Chavez, 2005; Ritchwood, DeCoster, Metzger, Bolland, \& Danielson, 2016) dan kecenderungan perilaku percobaan bunuh diri (Dragisic, Dickov, Dickov, \& Mijatovic, 2015).
Penyalahgunaan Napza juga dapat menimbulkan masalah yang merugikan pihak lain, seperti perilaku kekerasan kepada orang lain dalam kehidupan sehari-hari (Ansell, Laws, Roche, \& Sinha, 2015; Moore \& Stuart, 2005) dan perilaku kekerasan terhadap orang yang memiliki hubungan dekat (Smith, Homish, Leonard, \& Collins, 2013). Tidak hanya masalah perilaku kekerasan terhadap orang lain, penyalahgunaan Napza juga dapat menimbulkan perilaku kriminal yang juga merugikan orang lain (BNN, 2015; Rafaiee, Olyaee, \& Sargolzaiee, 2013).

Meskipun penyalahgunaan napza memberikan dampak negatif di berbagai aspek, tetapi jumlah kasus penyalahgunaan Napza di dunia masih cukup besar. Berdasarkan laporan dari United Nations Office on Drugs and Crime (UNDOC) (2016) diprediksi terdapat 247 juta orang yang menggunakan Napza pada tahun 2014 dan 29,5 juta diantaranya diduga mengalami masalah berkaitan dengan penggunaan Napza. Jumlah ini mengalami peningkatan dibandingkan tahun-tahun sebelumnya. Bahkan jika dibandingkan dengan prediksi jumlah pengguna Napza pada tahun 2008, peningkatan pengguna Napza di tahun 2014 mencapai 44 juta.

Di Indonesia pada tahun 2014 diprediksi terdapat 3,8 juta hingga 4,1 juta penyalahguna Napza (BNN, 2015). Dengan menggunakan skenario peningkatan jumlah penyalahgunaan napza, diprediksi pada tahun 2020 terdapat lima juta orang penyalahguna napza. Secara lebih spesifik, BNN (2016) melaporkan prevalensi penguna Napza pada kelompok pelajar dan mahasiswa di tahun 2016 mencapai 3,8\%. Prevalensi penggunaan Napza tertinggi pada tingkat pelajar dan mahasiswa yang berada pada masa remaja adalah di kota Yogyakarta yang mencapai $6,6 \%$. Selaras dengan 
temuan ini, Raesei, Sarani, Arbabisarjou, dan Mojahed (2015) mengemukakan bahwa onset penyalahgunaan Napza terbesar adalah pada masa remaja. Hal ini menegaskan bahwa kelompok remaja merupakan kelompok yang rawan untuk menyalahgunakan Napza.

Remaja merupakan masa ketika individu mengalami berbagai perubahan yang sangat cepat, baik dari segi fisik, emosional, ataupun psikososial (Newman \& Newman, 2012). Remaja juga memiliki kecenderungan untuk menunjukkan kemandirian. Dalam mencapai kemandirian dan identitas, remaja cenderung banyak melakukan perilaku berisiko yang bertujuan untuk coba-coba atau untuk memenuhi tekanan kelompok sebaya (Newman \& Newman, 2012; Steinberg, 2011).

Kelompok remaja dengan rentang usia 10 hingga 21 tahun berisiko mengalami berbagai masalah psikososial, salah satunya adalah masalah penyalahgunaan Napza (Steinberg, 2011). Tingkat masalah psikososial yang dialami oleh pecandu Napza dengan onset remaja di bawah 18 tahun lebih tinggi dibandingkan dengan onset penggunaan Napza di atas 18 tahun (Poudel \& Gautam, 2017). Hal ini mengindikasikan adanya peningkatan masalah psikososial yang akan dihadapi oleh remaja yang menyalahgunakan Napza.

Faktor risiko yang membuat remaja menggunakan Napza adalah adanya tekanan sebaya, banyaknya penggunaan dan peredaran Napza di kalangan remaja, dan adanya anggota keluarga yang menggunakan Napza (Kilpatrick et al., 2000; Steinberg, 2011). Pada rentang usia remaja hingga dewasa awal masalah yang menyebabkan penggunaan Napza adalah adanya teman yang buruk, sedangkan untuk usia yang lebih tua disebabkan karena emotional distress (Raesei et al., 2015). Hal ini mempertegas bahwa penyalahgunaan Napza di kalangan remaja lebih banyak dipicu karena faktor pengaruh sosial terutama teman sebaya, dibandingkan dengan masalah emosi.

Salah satu faktor protektif yang berkaitan dengan berbagai masalah penyalahgunaan Napza adalah efikasi diri. Efikasi diri merupakan konsep yang dikemukakan oleh Bandura (1977) sebagai keyakinan individu terhadap kompetensinya dalam menjalankan suatu tugas untuk mencapai tujuan tertentu. Keyakinan diri terhadap kompetensi yang dimiliki sangat bervariasi dan bergantung pada konteks. Terdapat beberapa macam efikasi seperti yang diungkapkan oleh Baron dan Byrne (2003), yaitu efikasi diri akademis dan efikasi diri sosial. Konsep terkait keyakinan seseorang atas kemampuannya mempertahankan diri dari pengaruh sosial untuk menyalahgunakan Napza pernah dikemukakan oleh Ellickson dan Hays (1990b) sebagai resistance self-efficacy. Ellickson dan Hays (1990b) menyebutkan bahwa rendahnya resistance self-efficacy dapat memprediksi secara langsung penggunaan Napza. Secara lebih lanjut konsep resistance self-efficacy telah dikembangkan oleh Carpenter (2006) menjadi drug use resistance self-efficacy (DURSE) dengan mengacu pada konsep Ellickson dan Hays (1990b).

Pada pecandu Napza yang menjalani rehabilitasi, efikasi diri berkorelasi negatif dengan relapse (Ibrahim, Kumar, \& Samah, 2011; Kadam, Sinha, Nimkar, Matcheswalla, \& De Sousa, 2017). Efikasi diri juga berperan terhadap lamanya masa abstinence pada pecandu Napza (Efditianur, 2018). Hal ini menegaskan bahwa pecandu Napza yang memiliki efikasi diri tinggi akan cenderung lebih bisa mempertahankan diri untuk tidak menyalahgunakan Napza kembali.

Efikasi diri merupakan faktor 
protektif bagi remaja untuk terhindar dari penyalahgunaan Napza (Sobti, 2010). Remaja yang memiliki efikasi diri tinggi lebih sedikit mengalami masalah penyalahgunaan Napza dan perilaku berisiko lain (Ludwig \& Pitmann, 1999). Efikasi diri pada remaja yang menyalahgunakan Napza secara signifikan lebih rendah dibandingkan dengan remaja yang tidak menyalahgunakan Napza (D'silva \& Aminabhavi, 2013).

Semakin tinggi efikasi diri pada remaja, maka risiko remaja untuk menyalahgunakan Napza akan semakin rendah. Efikasi diri memiliki korelasi negatif dengan penggunaan alkohol, rokok, dan ganja pada remaja (Zullig, Teoli, \& Valois, 2014). Hal ini selaras dengan beberapa penelitian yang mengungkapkan bahwa efikasi diri berpengaruh terhadap penurunan penggunaan alkohol remaja. (McKay, Sumnall, Cole \& Percy, 2012; Oei \& Jardim, 2007; Watkins, Howard-Barr, Moore, \& Werch, 2006).

Berdasarkan uraian di atas, dapat dipahami bahwa remaja memiliki risiko tinggi dalam masalah penyalahgunaan Napza. Penyalahgunaan Napza pada remaja juga akan memunculkan berbagai permasalahan yang berkaitan dengan aspek fisik, psikososial, dan perilaku yang dapat berujung kepada kematian. Oleh karena itu, diperlukan suatu program prevensi yang efektif untuk mencegah remaja terlibat dalam penyalahgunaan napza terutama yang bertujuan untuk meningkatkan efikasi diri remaja dalam menolak berbagai pengaruh sosial untuk menyalahgunakan Napza.

Berbagai program prevensi untuk mencegah remaja dalam masalah penyalahgunaan Napza telah banyak dilakukan. Ada program prevensi yang dilaksanakan dengan latar belakang dalam primary care setting (Walton et al.,
2014). Beberapa program dilakukan dalam setting keluarga dengan target partisipan universal atau populasi remaja secara umum (Fang \& Schinke, 2013; Mason et al., 2009; Pantin et al., 2009) dan target partisipan selektif (Stormshak et al., 2011). Program prevensi di sekolah dengan target partisipan universal (Spoth, Randall, Shin, \& Redmond, 2005) dan partisipan selektif (Mahu, Doucet, O'Leary-Barrett, \& Conrod, 2015) juga pernah dilakukan. Ada pula penelitian terkait dengan prevensi penyalahgunaan napza yang mengkolaborasikan antara setting sekolah dan setting keluarga (Spoth, Trudeau, Guyll, \& Shin, 2012; Spoth et al., 2013)

Prevensi penyalahgunaan Napza berbasis sekolah pada remaja secara umum menunjukkan efektivitasnya (Faggiano, Minozzi, Versino, \& Buscemi, 2014). Program prevensi berbasis sekolah dapat mencegah penggunaan Napza baik pada penggunaan yang jarang atau penggunaan yang lebih serius (Ellickson, McCaffrey, Dastidar, \& Longshore, 2003). Prevensi berbasis sekolah juga terbukti memberikan dampak yang lebih besar dalam mengurangi konsumsi alkohol dibandingkan dengan program berbasis keluarga (Das, Salam, Arshad, Finkelstein, \& Bhutta, 2016). Hal ini menunjukkan bahwa prevensi penyalahgunaan Napza pada remaja dapat efektif dilakukan dengan setting sekolah.

Yogyakarta sebagai kota dengan jumlah penyalahgunaan Napza terbesar pada tingkat pelajar masih belum menemukan program prevensi berbasis sekolah yang efektif. Salah satu program yang banyak dilakukan untuk mencegah penyalahgunaan napza di setting sekolah oleh pihak Badan Narkotika Nasional Provinsi (BNNP) Yogyakarta adalah Program Pencegahan dan Pemberantasan Penyalahgunaan Dan Peredaran Gelap Napza (P4GN). Berdasarkan penelitian 
yang dilakukan oleh Dewantara dan Ahdiyana (2016) program P4GN lebih mengarah pada kegiatan penyuluhan terkait bahaya Napza. Hal ini juga dikemukakan oleh Wulandari (2016) bahwa hasil program P4GN adalah bertambahnya jumlah siswa yang mendapatkan sosialisasi. Program berbasis peningkatan pengetahuan terkait napza tidak menunjukkan efek dalam melindungi remaja dari penyalahgunaan napza, tetapi dapat meningkatkan pengetahuan remaja tentang Napza (Faggiano et al., 2014). Berdasarkan penelitian lain, program yang hanya memberikan informasi tidak efektif untuk mencegah penggunaan Napza (Thomas, McLelland, \& Perera, 2013).

Di Indonesia, secara khusus di Yogyakarta penelitian terkait program prevensi penyalahgunaan Napza di kalangan remaja sudah pernah dilakukan, salah satunya adalah program "AJI". Program "AJI" disusun oleh Afiatin (2004) terbukti efektif meningkatkan pengetahuan, asertivitas, dan harga diri sebagai faktor protektif yang dapat mencegah kelompok remaja untuk menyalahgunakan Napza. Program lain yang diberi nama "Program Remaja Super" untuk meningkatkan efikasi diri sosial sebagai faktor protektif juga pernah disusun dan diuji, tetapi belum menunjukkan efektifitasnya (Yuserina, 2016). Hal ini menegaskan belum adanya program yang efektif untuk meningkatkan efikasi diri ataupun resistance self-efficacy sebagai faktor protektif bagi remaja untuk terhindar dari penyalahgunaan Napza.

Metode role-play adalah salah satu metode efektif yang dapat membantu remaja memiliki pengetahuan tentang bahaya Napza dan juga memiliki keterampilan untuk menolak pengaruh sosial untuk meyalahgunakan Napza. Secara khusus, program prevensi berbasis sekolah yang menggunakan metode role- play efektif untuk meningkatkan efikasi diri remaja untuk menolak penyalahgunaan Napza. Hal ini didasarkan pada penelitian yang telah dilakukan oleh Nozu et al. (2006) yang menunjukkan bahwa program prevensi berbasis sekolah pada remaja di Jepang dengan metode role-play dapat meningkatkan beberapa faktor protektif termasuk efikasi diri. Penelitian lain terkait prevensi penyalahgunaan Napza yang ditujukan pada remaja di Turki juga terbukti efektif untuk meningkatkan efikasi diri remaja untuk menolak penyalahgunaan Napza (Karatay \& Gürarslan Baş, 2017).

Beradasarkan uraian di atas, peneliti hendak melakukan intervensi berupa "Program Sehat Tanpa Napza". Program Sehat Tanpa Napza adalah program prevensi penyalahgunaan Napza berbasis sekolah untuk membantu remaja agar memiliki pemahaman yang benar terkait Napza dan bahaya yang ditimbulkan serta pengetahuan tentang cara menolak tekanan sosial untuk menyalahgunakan Napza. Program Sehat Tanpa Napza akan menggunakan role-play sebagai metode belajar yang telah terbukti dapat membantu remaja dalam meningkatkan efikasi diri remaja untuk menolak penyalahgunaan Napza. Pemahaman tentang Napza dan juga pengetahuan tentang cara menolak penyalahgunaan napza diharapkan dapat meningkatkan drug use resistance self-efficacy yang menjadi faktor protektif terkait masalah penyalahgunaan Napza di kalangan remaja.

\section{Metode}

Partisipan dalam penelitian ini adalah siswa kelas 8 SMP X $(N=53)$ dan SMP $Y$ $(\mathrm{N}=60)$ di Kota Yogyakarta. Penelitian ini menggunakan eksperimen kuasi dengan desain independent pretest-posttest with 
control group serta penambahan pengukuran 2 pekan setelah intervensi. Pembagian kelom pok dalam penelitian ini dilakukan tanpa adanya pengacakan dimana SMP adalah kelompok eksperimen yang mendapatkan intervensi berupa Program Sehat Tanpa Napza dan SMP Y adalah kelompok kontrol yang tidak mendapatkan intervensi. Pengukuran dilakukan sebanyak tiga kali pada kedua kelompok, yaitu satu pekan sebelum intervensi diberikan kepada kelompok eksperimen, langsung setelah intervensi selesai dilaksanakan, dan dua pekan setelah intervensi selesai diberikan pada kelompok eksperimen. Pengukuran pada kelompok kontrol dengan kelompok eksperimen berbeda satu hari menyesuaikan kesediaan pihak sekolah.

Pengukuran dilakukan dengan menggunakan Skala Drug Use Resistance Self-efficacy (DURSE) yang dikembangkan oleh Carpenter (2006) untuk mengukur kayakinan remaja untuk menolak pengaruh sosial dalam menggunakan Napza. Skala ini disusun berdasarkan aspek strength pada self-efficacy yang dibagi dalam dua faktor berdasarkan jenis Napza, yaitu resistensi terhadap alkohol/rokok dan resistensi terhadap ganja. Skala ini telah dimodifikasi oleh peneliti dengan melakukan perubahan aitem pertanyaan menjadi pernyataan dan penambahan aitem pengecoh. Hal ini dilakukan untuk meminimalkan adanya social desirability dalam pengisian skala. Aitem pengecoh tidak akan mendapatkan skor. Terdapat 8 aitem yang digunakan dengan koefisien korelasi internal bergerak dari 0,297-0,712. Delapan aitem ini juga dapat dikatakan reliabel yang dibuktikan dengan besarnya koefisien reliabilitas alpha sebesar 0,73.

Pengukuran juga dilakukan dengan menggunakan tes pengetahuan terkait materi Program Sehat Tanpa Napza. Hal ini dilakukan untuk melakukan uji manipulasi program sehat tanpa napza terhadap partisipan. Tes pengetahuan berisi 12 aitem dengan koefisien poin biserial bergerak dari 0,357-0,656. Tes pengetahuan ini juga dapat dikatakan reliabel dengan koefisien reliabilitas alpha sebesar 0,724 .

Intervensi yang diberikan kepada kelompok eksperimen berupa Program Sehat Tanpa Napza yang dilaksanakan sejumlah 3 pertemuan dengan durasi 40 menit untuk setiap pertemuan pada saat jam bimbingan konseling di kelas delapan SMP X. Intervensi yang diberikan mencakup beberapa hal berikut (tabel 1). 
Tabel 1.

Konten Modul Program Sehat Tanpa Napza

$\begin{array}{lll}\text { Aitem Konten } & \text { Tujuan } & \text { Kegiatan }\end{array}$

1. Pembukaan

2. Masalah

Penyalahgunaan

Napza pada Remaja

(Karatay \&

Gürarslan Baş, 2017;

Nozu et al., 2006).

3. Pengaruh sosial dan tekanan sebaya terhadap masalah penyalahgunaan Napza (Karatay \& Gürarslan Baş, 2017; Nozu et al., 2006).

4. Menolak pengaruh sosial untuk menyalahgunakan Napza (Karatay \& Gürarslan Baş, 2017; Nozu et al., 2006).

5. Mencari pertolongan bagi diri sendiri dan teman agar terhindar dari bahaya Napza (Karatay \& Gürarslan Baş, 2017).

6. Penutup
- Membangun hubungan baik dengan remaja

- Memberikan pemahaman tentang pentingnya isu penyalahgunaan Napza bagi remaja

- Memahamkan remaja tentang tujuan Program Sehat Tanpa Napza

- Meningkatkan pengetahuan remaja tentang penyalahgunaan Napza, meliputi pengertian penyalahgunaan Napza, ketergantungan Napza, serta bahaya penyalahgunaan Napza bagi fisik, psikologis, dan sosial.

- Meningkatkan pengetahuan remaja tentang pengaruh sosial dan tekanan sebaya terhadap masalah penyalahgunaan Napza.

- Meningkatkan pengetahuan tentang cara-cara yang efektif untuk menolak pengaruh sosial dalam menyalahgunakan Napza

- Meningkatkan pengetahuan remaja tentang pihak-pihak atau fasilitas yang dapat diakses untuk melindungi diri dan teman dari penyalahgunaan Napza

- Menjaga motivasi remaja untuk menerapkan pemahaman yang telah dimiliki selama sesi

- Terminasi
- Permainan "Saya memilih"

- Diskusi tentang isu penyalahgunaan Napza di kalangan remaja

- Ceramah tentang isu penyalahgunaan Napza

- Role-play “Menggunakan Napza untuk menghilangkan stres karena konflik dengan orang tua"

- Ceramah: pengertian penyalahgunaan Napza, ketergantungan Napza, serta bahaya penyalahgunaan Napza bagi fisik, psikologis, dan sosial.

- Diskusi

- Role-play: "Pakai Napza supaya keren!"

- Ceramah: Pengaruh sosial dan tekanan sebaya terhadap masalah penyalahgunaan Napza.

- Disuksi

- Role-play: “Diet dengan Napza untuk remaja putri"; "Napza menghilangkan lelah"

- Ceramah: cara-cara yang efektif untuk menolak pengaruh sosial dalam menyalahgunakan Napza.

- Role-play: “Tidak! Tidak! Tidak!”

- Diskusi

- Lomba membuat Jargon dan poster kreatif dengan tema "Remaja Sehat Tanpa Napza"

- Role-play: "Saya tidak sendiri"

- Diskusi

- Ceramah: pihak-pihak dan fasilitas yang dapat diakses untuk melindungi diri dan teman dari penyalahgunaan Napza

- Menampilkan jargon dan poster yang telah dibuat

- Meneriakkan jargon terpilih secara bersamasama

- Kesan dan pesan

- Kesimpulan dari peserta dan fasilitator 


\section{Hasil}

Penelitian dilakukan di SMP X $(\mathrm{N}=53)$ dan SMP Y $(N=60)$. SMP $X$ adalah kelompok eksperimen dan SMP Y adalah kelompok kontrol. Satu pekan sebelum kegiatan intervensi diberikan kepada kelompok eksperimen, pretest berupa pengisian skala DURSE dan Tes Tabel 2.

Data Deskriptif Hasil Penelitian juga adanya kegiatan mendadak dari pihak sekolah saat follow-up dilakukan. Jumlah peserta yang dapat dipertahankan adalah 62 partisipan dengan rincian 31 partisipan dari kelompok eksperimen dan 31 partisipan dari kelom pok kontrol. Tabel 2 dan gambar 1 menunjukkan data deskriptif hasil pretest, posttest, dan followup kelompok eksperimen dan kelompok

\begin{tabular}{lllll}
\hline \multicolumn{1}{c}{ Pengukuran } & \multicolumn{1}{c}{ Kelompok } & Total Skor & Rata-Rata Skor & N \\
\hline \multirow{2}{*}{ Pretest Pengetahuan } & Eksperimen & 247 & 7,967 & 31 \\
& Kontrol & 239 & 7,709 & 31 \\
Pretest DURSE & Eksperimen & 872 & 28,129 & 31 \\
& Kontrol & 938 & 30,258 & 31 \\
Posttest Pengetahuan & Eksperimen & 241 & 7,774 & 31 \\
& Kontrol & 239 & 7,709 & 31 \\
Posttest DURSE & Eksperimen & 874 & 28,193 & 31 \\
& Kontrol & 908 & 29,290 & 31 \\
Follow-up Tes Pengetahuan & Eksperimen & 264 & 8,516 & 31 \\
& Kontrol & 236 & 7,612 & 31 \\
Follow-up DURSE & Eksperimen & 926 & 29,87 & 31 \\
& Kontrol & 942 & 30,387 & 31 \\
\hline
\end{tabular}

Pengetahuan diberikan kepada kelompok eksperimen dan kontrol. Pretest dilakukan pada pekan yang sama, namun pada hari yang berbeda menyesuaikan kesediaan pihak sekolah. Skor skala DURSE yang dapat diperoleh minimal 8 dan maksimal 32. Sedangkan untuk tes pengetahuan skor minimal yang dapat diperoleh adalah 0 dan skor maksimal adalah 12 .

Namun demikian, terjadi mortalitas partisipan, baik di kelompok eksperimen ataupun kelompok kontrol. Hal ini dikarenakan ada beberapa siswa yang tidak secara rutin mengikuti kegiatan intervensi dari kelompok ekperimen dan kontrol.

Hasil uji anava campuran pada pengukuran tes pengetahuan menghasilkan nilai $F=1,405(p>0,05)$. Hal ini menunjukkan tidak adanya interaksi antara waktu (pretest, posttest, follow-up) dengan kelompok (eksperimen dan kontrol). Tidak adanya interaksi menunjukkan bahwa perubahan skor tes pengetahuan pretest, posttest, dan follow-up pada kedua kelompok (eksperimen dan kontrol) adalah tidak berbeda secara signifikan. Hal ini menunjukkan bahwa program sehat tanpa napza tidak dapat meningkatkan secara signifikan 
pengetahuan terkait konten materi dalam Program Sehat Tanpa Napza.

Hasil uji anava campuran pada pengukuran skala DURSE menghasilkan nilai $F=1,056(p>0,05)$ (lihat tabel 3). Hal ini menunjukkan tidak adanya interaksi antara waktu (pretest, posttest, follow-up) dengan kelompok (eksperimen dan kontrol). Tidak adanya interaksi menunjukkan bahwa perubahan skor pretest, posttest, dan follow-up pada kedua kelompok (eksperimen dan kontrol) dengan kelompok kontrol.

\section{Diskusi}

Penelitian ini bertujuan untuk mengetahui pengaruh Program Sehat Tanpa Napza untuk meningkatkan drug use resistance self-efficacy pada remaja sebagai upaya prevensi primer penyalahgunaan Napza di kalangan remaja. Hipotesis dalam penelitian ini adalah Program Sehat Tanpa Napza dapat meningkatkan drug use

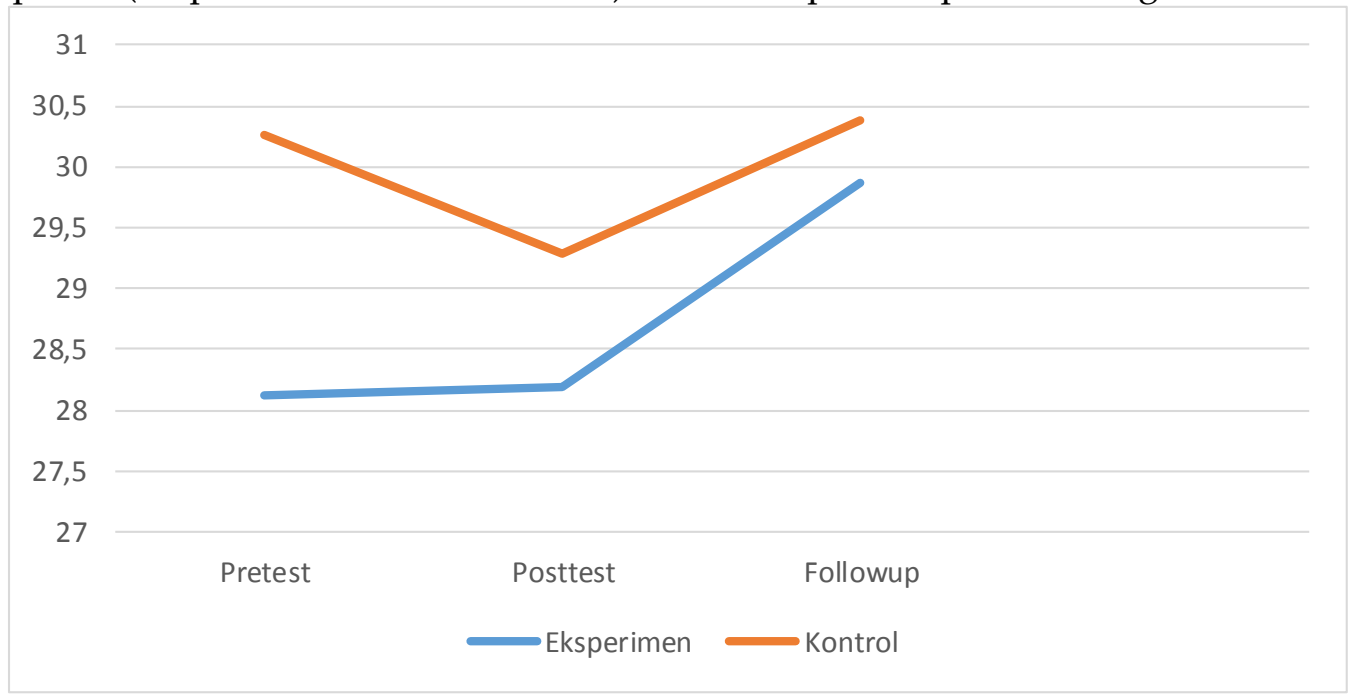

Gambar 1. Grafik rerata skor skala DURSE

adalah tidak berbeda secara signifikan. Hal ini menunjukkan bahwa Program Sehat Tanpa Napza tidak dapat meningkatkan secara signifikan drug use resistance self-efficacy pada remaja di kelompok eksperimen dibandingkan resistance self-efficacy pada remaja. Berdasarkan hasil uji statistika anava campuran diketahui bahwa Program Sehat Tanpa Napza tidak dapat meningkatkan secara signifikan drug use resistance selfefficacy pada remaja di

Tabel 3.

Hasil Uji Perbedaan Skor DURSE antara Pretest, Posttest, Follow-up pada Kelompok Eksperimen

\begin{tabular}{lllrrr} 
Group & $(\mathrm{I})$ time & $\mathbf{( J )}$ time & Mean Difference & $(\mathrm{I}-\mathrm{J})$ & \multicolumn{2}{c}{ Std. Error } & \multicolumn{2}{c}{ Sig. $^{b}$} \\
\hline Eksperimen & 1 & 2 &,- 065 &, 918 &, 944 \\
& & 3 & $-1,742^{*}$ &, 797 &, 033 \\
& 2 & 1 &, 065 &, 918 &, 944 \\
& & 3 & $-1,677^{*}$ &, 647 &, 012 \\
& 3 & 1 & $1,742^{*}$ &, 797 &, 033 \\
& 2 & $1,677^{*}$ &, 647 &, 012 \\
\hline E-JOURNAL GAMAJPP & & & & & 73
\end{tabular}


kelompok eksperimen jika dibandingkan dengan kelompok kontrol ( $\mathrm{F}=1,056$; $\mathrm{p}>$ 0,05). Hal ini menunjukkan bahwa hipotesis dalam penelitian ini ditolak.

Berdasarkan tinjauan lebih lanjut dari hasil data statistik deskriptif dapat diketahui bahwa kelompok eksperimen yang mendapatkan perlakukan berupa Program Sehat Tanpa Napza secara konsisten mengalami peningkatan rerata skor skala DURSE. Hal ini menunjukkan adanya peningkatan drug use resistance selfefficacy pada partisipan yang mendapatkan Program Sehat Tanpa Napza. Jika mengacu pada desain eksperimen kuasi yang dilakukan oleh Karatay \& Gürarslan Baş (2017), maka didapatkan temuan yang serupa yakni adanya peningkatan skor dari pretest dan posttest menuju ke follow-up dalam 2 pekan. Sedangkan pada kelompok kontrol yang tidak mendapatkan Program Sehat Tanpa Napza menunjukkan hasil rerata yang cenderung fluktuatif, yakni mengalami penurunan pada saat posttest dan mengalami peningkatan pada saat follow-up. Hal ini menunjukkan bahwa peningkatan skor skala DURSE pada partisipan yang tidak mendapatkan Program Sehat Tanpa Napza cenderung tidak tetap.

Peningkatan skor pada kelompok eksperimen dari pretest menuju posttest yang dilakukan langsung setelah intervensi tidak signifikan. Peningkatan skor dari pretest dan posttest ke follow-up dalam jangka waktu 2 pekan pada kelompok eksperimen menunjukkan adanya signifikansi (lihat tabel 3). Hal ini menegaskan Bahwa Program Sehat Tanpa Napza yang diberikan pada kelompok eksperimen dapat meningkatkan drug use resistance selfefficacy setelah adanya jeda waktu setidaknya dua pekan. Hasil ini selaras dengan temuan beberapa penelitian bahwa efikasi diri untuk menolak tekanan sebaya dalam menyalahgunakan Napza meningkat dalam jeda waktu tertentu, setidaknya dua pekan setelah intervensi (Heyne \& Bogner, 2009; Karatay \& Gürarslan Baş, 2017; Nozu et al., 2006).

Berbagai penelitian menunjukkan bahwa efikasi diri merupakan salah satu faktor protektif untuk mencegah remaja dalam menyalahgunakan Napza (Ellickson dan Hays, 1990a; McKay et al., 2012; Oei dan Jardim, 2007; Watkins et al., 2006). Secara khusus konsep terkait keyakinan seseorang atas kemampuannya mempertahankan diri dari pengaruh sosial untuk menyalahgunakan Napza telah dikemukakan oleh Ellickson dan Hays (1990a) sebagai resistance self-efficacy. Ellickson dan Hays (1990a) menyebutkan bahwa rendahnya resistance self-efficacy dapat memprediksi secara langsung penggunaan Napza. Secara lebih lanjut konsep resistance self-efficacy telah dikembangkan oleh Carpenter (2006) menjadi drug use resistance self-efficacy (DURSE) dengan mengacu pada konsep Ellickson dan Hays (1990a).

Drug use resistance self-efficacy dapat ditingkatkan melalui empat sumber efikasi diri yang dikemukakan oleh Bandura (1997), yaitu mastery experience (menguasai pengalaman sukses diri sendiri), vicarious experience (mengamati pengalaman sukses orang lain), verbal persuasion (dukungan secara verbal), dan somatic-emotional states (kondisi dan persepsi terhadap keadaan fisik serta emosional). Berbagai sumber efikasi ini kemudian difasilitasi untuk didapatkan melalui Program Sehat Tanpa Napza yang menggunakan role-play sebagai metode utama.

Role-play melibatkan seseorang untuk berada pada suatu situasi atau skenario untuk melatih diri dalam menghadapi orang lain ataupun situasi tersebut (Bonwell \& Eison, 1991). Latihan dalam bentuk role-play ini akan membantu 
peserta untuk belajar menguasai pengalaman terkait keberhasilannya dalam menolak tekanan sebaya untuk menyalahgunakan Napza (mastery experience). Selain itu, role-play juga memungkinkan peserta untuk mendapatkan pembelajaran sosial terkait cara menolak tekanan sebaya untuk menyalahgunakan Napza yang diperankan oleh teman-temannya (vicarious experience). Jika pengamat melihat bahwa model yang diamati sangat berbeda dengan dirinya maka efikasi dirinya tidak akan dipengaruhi oleh perilaku model ataupun hasil yang didapatkan (Bandura, 1994). Maka, dalam hal ini role-play yang diperankan langsung oleh siswa dari kelas dan sekolah yang sama menjadi sebuah keunggulan dimana siswa yang memerankan cara menolak tekanan sosial secara umum memiliki kesamaan karakter dengan peserta lain.

Pada pelaksanaan Program Sehat Tanpa Napza juga dilakukan berbagai bentuk dukungan verbal baik dari fasilitator ataupun peserta yang dapat menjadi sumber verbal persuation dalam meningkatkan drug use resistance selfefficacy. Salah satunya adalah dengan kompetisi jargon untuk menghindari Napza. Seseorang yang dipersuasi secara verbal bahwa dia memiliki kemampuan untuk menyelesaikan tugas yang diberikan akan memunculkan usaha yang lebih keras dan mampu untuk bertahan dengan usaha tersebut (Bandura, 1994). Maka, persuasi verbal yang ada dalam Program Sehat Tanpa Napza akan membantu peserta dalam melakukan usaha lebih keras dan mempertahankan upaya untuk menolak tekanan sebaya dalam menyalahgunakan Napza.

Program Sehat Tanpa Napza tidak secara khusus memfasilitasi sumber somatic-emotional states. Hal ini dikarenakan pendekatan social influence yang digunakan dalam Program Sehat
Tanpa Napza tidak memasukkan berbagai teknik untuk menjaga stabilitas emosi dan fisik sebagai bagian dari program. Hal ini menjadi salah satu limitasi dalam penelitian ini.

Proses terbentuknya efikasi diri yang baik juga dipengaruhi oleh adanya lingkungan yang mendukung untuk mengembangkan efikasi diri Tripp, Herrmann, Parcel, Chamberlain, dan Gritz (dalam Brown, Malouff, \& Schutte, 2013). Hal ini menunjukkan bahwa keterlibatan guru di sekolah dan juga pihak orang tua penting dalam mengembangkan drug use resistance self-efficacy pada remaja. Namun demikian, dikarenakan pendekatan prevensi berbasis sekolah yang dilakukan membatasi adanya keterlibatan orang tua, maka tidak terlibatnya orang tua menjadi limitasi dalam penelitian ini yang dimungkinkan memengaruhi tidak signifikannya peningkatan skor skala DURSE. Selain itu, guru juga belum terlibat dalam penelitian Program Sehat Tanpa Napza. Hal ini dikarenakan adanya upaya peneliti untuk menghindari adanya otoritas yang dimiliki guru untuk memberikan perintah terhadap siswa sehingga hasil peningkatan skor skala DURSE menjadi bias.

Sebagai upaya peningkatan drug use resistance self-efficacy pada remaja, Program Sehat Tanpa Napza dilakukan dengan meningkatkan pengetahuan tentang Napza dan bahayanya serta kemampuan atau keterampilan untuk menolak tekanan sebaya dalam menyalahgunakan Napza (Karatay \& Gürarslan Baş, 2017; Nozu et al., 2006). Program prevensi penyalahgunaan Napza perlu memberikan pengetahuan tentang masalah penyalahgunaan Napza dan juga cara untuk menolak tekanan sosial dalam menyalahgunakan Napza. Hal ini dikarenakan program yang hanya memberikan informasi bahaya Napza tidak efektif untuk mencegah penggunaan 
napza (Thomas, McLelland, \& Perera, 2013).

Pengetahuan tentang penyalahgunaan Napza dan cara untuk menolak penyalahgunaan Napza yang didapat dari Program Sehat Tanpa Napza diharapkan mampu meningkatkan drug use resistance self-efficacy melalui sumber-sumber selfefficacy sebagai faktor protektif yang dapat melindungi remaja dari penyalahgunaan Napza. Hal ini menegaskan bahwa untuk menjelaskan tidak adanya pengaruh Program Sehat Tanpa Napza dalam meningkatkan drug use resistance selfefficacy secara signifikan perlu melihat pemahaman materi peserta.

Berdasarkan hasil cek manipulasi, diketahui bahwa program sudah berjalan sesuai dengan modul. Hal ini menunjukkan bahwa setiap kegiatan yang disusun berdasarkan konten materi dalam modul telah disampaikan secara keseluruhan oleh fasilitator kepada partisipan kelompok eksperimen. Namun demikian, hasil analisis tes pengetahuan dengan anava campuran tidak menunjukkan adanya interaksi antara waktu (pretest, posttest, follow-up) dengan kelompok (eksperimen dan kontrol). Tidak adanya interaksi menunjukkan bahwa perubahan skor tes pengetahuan pretest, posttest, dan follow-up pada kedua kelompok (eksperimen dan kontrol) adalah tidak berbeda secara signifikan. Hal ini menunjukkan bahwa program sehat tanpa napza tidak dapat meningkatkan pengetahuan terkait konten materi dalam Program Sehat Tanpa Napza secara signifikan.

Tidak adanya peningkatan secara signifikan terkait pengetahuan konten materi Program Sehat Tanpa Napza dapat menjadi indikasi belum optimalnya peserta dalam menerima materi sehingga berpengaruh terhadap tidak adanya signifikansi perubahan drug use resistance self-efficacy. Berdasarkan hasil observasi, diketahui bahwa pada saat pemaparan materi beberapa peserta cenderung tidak memperhatikan dan ada yang melakukan aktivitas lain di luar aktivitas pelatihan. Kurang optimalnya peserta dalam menyerap materi akan mempengaruhi proses dalam menguasai pengalaman (mastery experience) yang merupakan salah satu sumber penting dalam membentuk efikasi diri (Bandura, 1997).

$$
\text { Selain belum optimalnya }
$$
pemahaman materi yang didapat oleh peserta, faktor mortalitas partisipan juga memiliki peran terhadap tidak berpengaruhnya Program Sehat Tanpa Napza dalam meningkatkan drug use resistance self-efficacy secara signifikan. Mortalitas yang dapat diartikan sebagai hilangnya sejumlah partisipan tertentu dapat mengakibatkan perubahan pada rata-rata skor variabel dependen setelah perlakuan (Azwar, 2018). Pada penelitian ini terdapat perubahan jumlah peserta yang mengikuti pretest dengan yang mengikuti posttest dan folllow-up. Terdapat 53 partisipan kelompok ekperimen dan 68 partisipan di kelompok kontrol yang mengikuti pretest. Namun, dikarenakan ada beberapa peserta dari kelompok eksperimen yang tidak mengikuti penuh kegiatan serta adanya kegiatan mendadak diluar prediksi peneliti yang membuat beberapa peserta tidak dapat mengikuti follow-up, maka hanya tersisa 62 peserta yang datanya dapat diproses (31 peserta kelompok eksperimen dan 31 peserta kelompok kontrol).

Faktor lain yang juga diduga menjadi salah satu penyebab tidak ditemukannya pengaruh Program Sehat Tanpa Napza dalam meningkatkan drug use resistance self-efficacy remaja adalah terkait kondisi fisik dan psikis peserta saat menjalankan program dan mengisi skala. Program Sehat Tanpa Napza dilakukan pada saat jam BK yang ada di lokasi penelitian. Hal ini membuat peneliti tidak 
bisa memilih atau mengendalikan aktivitas partisipan sebelum menjalankan Program Sehat Tanpa Napza yang dimungkinkan dapat mempengaruhi kondisi fisik dan emosi peserta. Program Sehat Tanpa Napza dijalankan pada kelompok eksperimen setelah jam olahraga dan pada jam terakhir. Dua waktu ini dinilai kurang kondusif oleh peneliti karena dapat menyebabkan kelelahan fisik (jam olahraga) dan membuat kondisi emosi peserta cenderung tidak pada kondisi nyaman (tergesa-gesa ingin segera pulang pada jam terakhir). Adanya kondisi fisik dan emosional yang cenderung tidak stabil ini dapat mempengaruhi tidak diperolehnya pengaruh Program Sehat Tanpa Napza dalam meningkatkan drug use resistance self-efficacy remaja secara signifikan. Hal ini dikarenakan kondisi fisik dan emosional yang stabil merupakan salah satu sumber terbentuknya efikasi diri (Bandura, 1997)

Di luar berbagai keterbatasan penelitian ini yang memungkinkan membuat Program Sehat Tanpa Napza tidak dapat meningkatkan drug use resistance self-efficacy remaja secara signifikan, ada beberapa nilai positif yang perlu didiskusikan untuk mendapatkan pemahaman yang lebih optimal terkait temuan hasil penelitian. Penelitian ini didesain dengan seting ruang kelas sehingga dapat menghasilkan beberapa keuntungan, yaitu memungkinkan untuk mendapatkan evaluasi hasil penelitian yang relevan dengan realita di lapangan serta mudah diterapkan bagi guru BK pada setting kelas dengan memasukkannya ke dalam kurikulum materi BK.

Desain ekperimen kuasi dalam penelitian ini lebih kompleks dibandingkan dengan penelitian yang dilakukan oleh Karatay \& Gürarslan Baş (2017). Hal ini akan berdampak pada didapatkannya gambaran hasil dan evaluasi yang lebih detail terkait program prevensi primer penyalahgunaan Napza pada remaja dengan pendekatan pengaruh sosial yang menggunakan roleplay sebagai metode utama. Hal ini ditegaskan dengan adanya temuan yang sama anatara penelitian ini dengan penelitian Karatay \& Gürarslan Baş (2017) yang menggunakan desain pretest dan posttest pada kelompok tunggal serta didapatkan temuan yang berbeda pada desain penelitian independent pretest-postest control group.

\section{Kesimpulan}

Program Sehat Tanpa Napza tidak dapat meningkatkan secara signifikan drug use resistance self-efficacy pada remaja di kelompok eksperimen dibandingkan dengan kelompok kontrol. Namun demikian, Program Sehat Tanpa Napza dapat meningkatkan drug use resistance self-efficacy kelompok eksperimen secara signifikan pada pengukuran dua pekan setelah intervensi. Hal ini menjelaskan bahwa keyakinan individu dalam menolak tekanan sosial untuk menyalahgunakan Napza dapat meningkat setidaknya dalam waktu dua pekan setelah intervensi. Adapun faktor yang diduga menyebabkan Program Sehat Tanpa Napza tidak dapat meningkatkan drug use resistance self-efficacy secara signifikan pada remaja di kelompok eksperimen dibandingkan dengan kelompok kontrol adalah sebagai berikut: (1) tidak dilibatkannya orang tua dan guru dalam Program Sehat Tanpa Napza yang dapat memengaruhi tidak optimalnya peningkatan efikasi diri pada remaja (2) Tidak optimalnya penyerapan materi pada peserta yang berpengaruh pada sumber efikasi diri berupa mastery experience (3) mortalitas partisipan penelitian yang memengaruhi perubahan 
mean sehingga dapat berdampak pada signifikansi pengukuran statistik.

Saran

Peneliti selanjutnya diharapkan mampu untuk mempertimbangkan untuk melibatkan orang tua dan guru dalam program. Selain itu, peneliti selanjutnya juga diharapkan dapat meningkatkan jumlah partisipan serta dapat menggunakan desain penelitian eksperimen acak untuk mendapatkan hasil serta evaluasi yang lebih akurat.

\section{Daftar Pustaka}

Afiatin, T., (2004). Pengaruh program kelompok "AJI" dalam peningkatan harga diri, asertivitas, dan pengetahuan mengenai Napza untuk prevensi penyalahgunaan Napza pada remaja. Jurnal Psikologi, 31(1), 28-54. doi: 10.22146/jpsi.7035

Ames, M. E., Rawana, J. S., Gentile, P. \& Morgan, A. S. (2015). The protective role of optimism and self-esteem on depressive symptom pathways among canadian aboriginal youth. $J$ Youth Adolescence, 44(142). doi: 10.1007/s10964-013-0016-4

Ansell, E. B., Laws, H. B., Roche, M. J., \& Sinha, R. (2015). Effects of Marijuana use on impulsivity and hostility in daily life. Drug and Alcohol Dependence, 148, 136-142. doi: 10.1016/j.drugalcdep.2014.12.029

Azwar, S. (2018). Metode penelitian psikologi (Edisi kedua). Yogyakarta: Pustaka Pelajar.

Badan Narkotika Nasional. (2015). Survei nasional perkembangan penyalahounaan napza 2014. Laporan Akhir BNN 2014. Diunduh dari http://www.bnn.go.id/read/pressrel ease/12691/laporan-akhir-surveinasional-perkembanganpenyalahguna-napza-tahun- anggaran-2014

Badan Narkotika Nasional. (2016). Hasil survei penyalahgunaan dan peredaran gelap napza pada kelompok pelajar dan mahasiswa di 18 provinsi tahun 2016. Ringkasan Eksekutif. Diunduh dari http://yogyakarta.bnn.go.id/index.p hp?option=com dropfiles\&format $=$ \&task=frontfile. download\&catid $=88$ \&id=55\&Itemid $=1000000000000$

Bandura, A. (1977). Self-efficacy: Toward a unifying theory of behavioral change. Psychological Review, 34(2). 191-215. doi: 10.1037/0033295X.84.2.191

Bandura, A. (1997). Self-efficacy: The excercise of control. New York: W.H. Freem an and Company.

Bandura, A. (1994). Social cognitive theory of mass communication. In J. Bryant \& D. Zillmann (Eds.), LEA's communication series. Media effects: Advances in theory and research ( $p p$. 61-90). Hillsdale, NJ, US: Lawrence Erlbaum Associates, Inc.

Baron, R. A., \& Byrne, D. (2003). Psikologi sosial edisi kesepuluh (Terjemahan). Jakarta: Penerbit Erlangga.

Barthelemy, O. J., Richardson, M. A., Cabral, H. J. \& Frank, D. A. (2016). Prenatal, perinatal, and adolescent exposure to marijuana: Relationships with aggressive behaviour. Neurotoxicology and Teratology, 58(2016), 60-77. doi: 10.1016/j.ntt.2016.06.009

Brown, L. J., Malouff, J. M., \& Schutte, N. S. (2013). Self-efficacy theory. Paper. Australia: University of New England.

Bonwell, C. C., \& Eison, J. A. (1991). Active learning: Creating excitement in the classroom. Washington, DC: The George Washington University.

Carpenter, C. M. (2006). Development of a scale to measure adolescents' drug use resistance self-efficacy (Doctoral 
dissertation). University of Maryland, College Park USA.

D' Silva, J \& Aminabhavi, V. A. (2013). Adjustment, self-efficacy and psychosocial competency of drug addicted adolescents. Journal of Psychology. 4(1), 13-18. doi: $\underline{\text { 10.1080/09764224.2013.11885489 }}$

Das, J. K., Salam, R. A., Arshad, A., Finkelstein, Y., \& Bhutta, Z. A. (2016). Intervention for adolescent substance abuse: An overview of systematic review. The Journal of Adolescent Health, 59, S61-S75. doi: 10.1016\%2Fj.jadohealth.2016.06.021

Dewantara, N. N., \& Ahdiyana, M. (2016). Pelaksanaan Program Pencegahan dan Pemberantasan Penyalahgunaan dan Peredaran Gelap Napza (P4GN) di kalangan pelajar di kota Yogyakarta. Diunduh dari

http://journal.student.uny.ac.id/ojs/i ndex.php/adinegara/article/downlo $\mathrm{ad} / 2490 / 2138$

Dragisic, T., Dickov, A., Dickov, V., \& Mijatovic, V. (2015). Drug addiction as risk for suicide attempts. Materia Socio-Medica， 27(3), 188-191. doi: $\underline{10.5455 / \mathrm{msm} .2015 .27 .188-191}$

Efditianur, D. (2018). Peran koping terhadap lamanya masa abstinence penyalahounaan napza dengan mediator efikasi diri dan percieved social support (Tesis master tidak dipublikasikan). Yogyakarta: Universitas Gadjah Mada.

Ellickson, P. L., \& Hays, R. D. (1990a). Beliefs about resistance self-efficacy and drug prevalence: Do they really affect drug use?. Int J. Addict 25(11A), 1353-78. Diunduh dari https://www.ncbi.nlm.nih.gov/pub med/2132718

Ellickson, P. L., \& Hays, R. D. (1990b). How generalizable are adolescents' beliefs about pro-drug pressures and resistance self-efficacy?. Journal of Applied Psychology, 20(4), 321-340. doi: $\underline{10.1111 / \mathrm{j} .1559-}$

1816.1990.tb00414.x

Ellickson, P. L., McCaffrey, D. F., Dastidar, B. G., \& Longshore, D. L. (2003). New inroads in preventing adolescent drug use: Result from a large-scale trial of project ALERT in middle schools. American Journal of Public Health, 93, 1830-1836.

Faggiano F, Minozzi S, Versino E, \& Buscemi D. (2014). Universal schoolbased prevention for illicit drug use. Cochrane Database of Systematic Reviews, 2014(12). doi: 10.1002/14651858. CD003020.pub3

Fang, L., \& Schinke, S. P. (2013). Two-year outcomes of a randomized, familybased substance use prevention trial for Asian American adolescent girls. Psychology of Addictive Behaviors. 27(3), 788-798. doi: $10.1037 \% 2 \mathrm{Fa} 0030925$

Halgin, R. P., \& Whitbourne, S. K. (2010). Psikologi abnormal perspektif klinis pada gangguan psikologis. Jakarta: Salemba Humanika.

Heyne, T., \& Bogner, F. X. (2009). Strengthening resistance selfefficacy: Influence of teaching approaches and gender on different consumption groups. Journal of Drug Education, 39(4), 430-457. doi: 10.2190\%2FDE.39.4.f

Hidayat, F. (2016). Dampak sosial penyalahgunaan napza pada remaja di kelurahan kalabbirang kecamatan pattallassang kabupaten takalar (Skripsi tidak dipublikasikan). UIN Alauddin, Makassar.

Ibrahim, F., Kumar, N., \& Samah, B. A. (2011). Self-efficacy and relapsed addiction tendency: An empirical study. The Social Sciences, 6(4), 277282. 10.3923/sscience.2011.277.282

Kadam, M., Sinha, A., Nimkar, S., 
Matcheswalla, Y., \& De Sousa, A. (2017). A comparative study of factors associated with relapse in alcohol dependence and opioid dependence. Indian Journal of Psychological Medicine, 39(5). doi: 10.4103/IJPSYM.IJPSYM_356_17

Karatay, G., \& Gürarslan Bas, N. (2017). Effects of role-playing scenarios on the self-efficacy of students in resisting against substance addiction: a pilot study. INQUIRY: The Journal of Health Care Organization, Provision, and Financing, 54, 1-6. doi: 10.1177/ $\underline{0046958017720624}$

Kieling, C., Graeff-Martins A. S., Hamoda, H., \& Rohde L. A. (2014). Child and adolescent mental health. In Vikram, P., Harry, M., Alex, C., and Martin, J. P. (eds), Global mental health principle and practice. New York: Oxford University Press.

Kilpatrick, D. G., Acierno, R., Saunders, B., Resnick, H. S., Best, C. L., \& Schnurr, P. P. (2000). Risk factors for adolescent substance abuse and dependence: Data from a national sample. Journal of Consulting and Clinical Psychology, 68(1), 19-30. doi: 10.1037/0022-006X.68.1.19

Konpf, D., Park, M. J., \& Mulye, T. P. (2008). The mental health of adolescents: A national profile, 2008. NAHIC. Diunduh dari http://nahic.ucsf.edu/downloads/M entalHealthBrief.pdf

Ludwig, K. B., \& Pittman, J. F. (1999). Adolescent prosocial values and self-efficacy in relation to delinquency, risk sexual behavior, and drug use. Youth $\mathcal{E}$ Society, 30(4), 461-482. doi: 10.1177\%2F0044118X99030004004

Mahu, I. T., Doucet, C., O'Leary-Barrett, M., \& Conrod P. J. (2015). Can cannabis use be prevented by targeting personality risk in schools? 24-month outcome of the adventure trial on cannabis use: A cluster randomized controlled trial. Addiction, 110(10), 1625-1633. doi: 10.1111/add.12991

Mason, W. A., Kosterm an, R., Haggerty, K. P., Hawkins, J. D., Redmond, C., Spoth, R. L., \& Shin, C. (2009). Gender moderation and social developmental mediation of the effect of a family-focused substance use preventive intervention on young adult alcohol abuse. Addictive Behaviors, 34(6), 599-605. doi: 10.1016\%2Fj.addbeh.2009.03.032

McKay, M. T., Sumnall, H. R., Cole, J. C. \& Percy. (2012). Self-esteem and selfefficacy: associations with alcohol consumption in a sample of adolescents in Northern Irelan. Drug: Education, Prevention, and Poilicy, 19(1), 72-80. doi: 10.3019/ 09687637.2011.579585

Moore, T. M., \& Stuart, G. M. (2005). A review of the literature on marijuana and interpersonal violence. Aggression and Violent Behavior, 10(2005), 171-192. doi: 10.1016/ j.avb.2003.10.002

Mulyati, R. (2009). Resiliensi remaja highrisk ditinjau dari faktor protektif. Psikologika, 14(1), 35-53. Diunduh dari http://www.jurnal.uii.ac.id/ Psikologika/article/view/4128/3677

Newman, B. M., \& Newman, P. R. (2012). Life-span development: A psychosocial approach. Canada: Wardswort Cengage Learning.

Nozu, Y., Watanabe, M., Kubo, M., Sato, Y., Shibata, N., Uehara, C., Kikuchi, N., Kawahara, K., Takahashi, N., \& Kito, H. (2006). Effectiveness of drug abuse prevention program focusing on social influences among high school students: 15-month follow-up study. Environmental Health and 
Preventive Medicine, 11, 75-81. doi: $10.1007 \% 2 \mathrm{FBF} 02898146$

Oei, T. P. S., \& Jardim, C. L. (2007). Alcohol expectancies, drinking refusal selfefficacy and drinking behaviour in Asian and Australian students. Drug and Alcohol Dependence, 87, 281-287. doi:

10.1016/j.drugalcdep.2006.08.019

Pantin, H., Prado, G., Lopez, B., Huang, S., Tapia, M.I., Schwartz, S. J., \& Branchini, J. (2009). A randomized controlled trial of familias unidas for Hispanic adolescents with behavior problems. Psychosomatic Medicine, 71(9), 987-995. doi: 10.1097/PSY.0b013e3181bb2913

Pillon, S. C., O'Brien, B., \& Chavez K. A. P. (2005). The relationship between drugs use and risk behaviors in Brazilian University students. Rev Latino-am Enfermagem, 13, 1169-1176. Diunduh dari www.eerp.usp.br/ilae

Possi, M. K. (1996). Effects of drug abuse on cognitive and social behaviours: A potential problem among youth in Tanzania. UTAFITI (New Series), 3(1), 111-128.

Poudel, A., \& Gautam, S. (2017). Age of onset of substance use and psychosocial problems among individuals with substance use disorders. BMC Psychiatry, 17(10), 17. doi: 10.1186/s12888-016-1191-0

Raeisei, A., Sarani, H., Arbabisarjou, A., \& Mojahed, A. (2015). The most common reasons and incentives of tendency to addiction in prisons and rehabilitation centres of Zahedan (Iran). Global Journal of Health Science, 7(4), 329-334. doi: 10.5539\%2Fgihs.v7n4p329

Rafaiee, R., Olyaee, S., \& Sargolzaiee, A. (2013). The relationship between the type of crime and drugs in addicted prisoners in zahedan central prison. International Journal of High Risk
Behaviors \& Addiction, 2(3), 139-140. doi: $\underline{10.5812 / \text { ijhrba.13977 }}$

Ritchwood, T. D., DeCoster, J., Metzger, I. W., Bolland, J. M., Danielson, C. K. (2016). Does it really matter which drug you choose? An examination of the influence of type of drug on type of risky sexual behavior. Addictive Behavior, 60(2016), 97-102. doi: 10.1016/j.addbeh.2016.03.022

Smith, P. H., Homish, G. G., Leonard, K. E., \& Collins, R. L. (2013). Marijuana withdrawal and aggression among a representative sample of U.S. marijuana users. Drug and Alcohol Dependence, 132(2013), 63-68. doi: 10.1016/j.drugalcdep.2013.01.002

Sobti, V. (2010). A comparative study of substance abusers and non-users on self-efficacy, stress and coping among high school students. Journal of Psychosocial Research, 5(2), 283-290. Diunduh dari

https://search.proquest.com/docvie $\mathrm{w} / 862714200$ ?accountid=13771

Spoth, R. L., Randall, G. K., Shin, C., \& Redmond, C. (2005). Randomized study of combined universal family and school preventive interventions: Patterns of long-term effects on initiation, regular use, and weekly drunkenness. Psychology of Addictive Behaviors, 19(4), 372-381. doi: 10.1037/0893-164X.19.4.372

Spoth, R. L., Trudeau, L. S., Guyll, M., \& Shin, C. (2012). Benefits of universal intervention effects on a youth protective shield 10 years after baseline. Journal of Adolescent Health, 50(4), 414-417. doi: 10.1016/j.jadohealth.2011.06.010

Spoth, R. L., Trudeau, L., Shin, C., Ralston, E., Redmond, C., Greenberg, M., \& Feinberg, M. (2013). Longitudinal effects of universal preventive intervention on prescription drug misuse: Three randomized 
controlled trials with late adolescents and young adults. American Journal of Public Health, 103(4), 665-672. doi: 10.2105/AJPH.2012.301209

Steinberg, L. (2011). Adolescence (9th Ed). New York: MoGraw-Hill.

Stormshak, E. A., Connell, A. M., Véronneau, M. H., Myers, M. W., Dishion, T. J., Kavanagh, K. , \& Caruthers, A. S. (2011). An ecological approach to promoting early adolescent mental health and social adaptation: $\quad$ Family-centered intervention in public middle schools. Child Development, 82(1), 209-225. doi: 10.1111/j.1467$\underline{\text { 8624.2010.01551.x }}$

Thomas R. E., McLellan J., \& Perera R. (2013). School-based programmes for preventing smoking. Cochrane Database of Systematic Reviews, 2013(4), 1-425. doi: 10.1002/14651858.CD001293.pub3

United Nations Office on Drugs and Crime (UNODC). (2016). World drug report 2016 (United Nations publication, Sales No. E.16.XI.7). Diunduh dari https://www.unodc.org/doc/wdr201 6/WORLD DRUG_REPORT 2016 web.pdf
Walton, M. A., Resko, S., Barry, K. L., Chermack, S. T., Zucker, R. A., Zimmerman, M. A., \& Blow, F. C. (2014). A randomized controlled trial testing the efficacy of a brief cannabis universal prevention program among adolescents in primary care. Addiction. 109(5), 786797. doi: $10.1111 /$ add.12469

Watkins, J. A., Howard-Barr, E. M., Moore, M. J., \& Werch, C. C. (2006). The mediating role of adolescent selfefficacy in the relationship between parental practices and adolescent alcohol use. Journal of Adolescent Health, 38(4), 448-450. doi: 10.1016/j.jadohealth.2005.04.002.

Wulandari, T. (2016). Implementasi kebijakan pencegahan dan pemberantasan penyalahgunaan dan peredaran gelap napza (P4GN) pada kalangan pelajar di badan narkotika nasional provinsi (BNNP) Daerah Istimewa Yogyakarta (Skripsi Program Sarjana). Universitas Negeri Yogyakarta, Yogyakarta.

Yuserina, F. (2016). Program remaja super untuk meningkatkan efikasi diri sosial pada remaja: Usaha prevensi penyalahgunaan NAPZA (Tesis). Universitas Gadjah Mada, Yogyakarta.

Zullig, K. ., Teoli, D. A., \& Valois, Robert F. (2014). Emotional self-efficacy and alcohol and tobacco use in adolescents. Journal of Drug Education: Substance Abuse Research and Prevention, 44(1-2), 51-66. 